\title{
Recall of Theoretical Pharmacology Knowledge by 6th Year Medical Students and Interns of Three Medical Schools in Riyadh, Saudi Arabia
}

\author{
A. A. Mustafa, ${ }^{1}$ H. A. Alassiry, ${ }^{1,2}$ A. Al-Turki, ${ }^{2}$ N. Alamri, ${ }^{2}$ \\ N. A. Alhamdan, ${ }^{1}$ and Abdalla Saeed ${ }^{3}$ \\ ${ }^{1}$ Faculty of Medicine, KFMC, P.O. Box 59046, Riyadh 11525, Saudi Arabia \\ ${ }^{2}$ King Saud bin Abdulaziz University for Health Sciences, P.O. Box 3660, Riyadh 11481, Saudi Arabia \\ ${ }^{3}$ Community Medicine, Faculty of Medicine, KFMC, P.O. Box 59046, Riyadh 11525, Saudi Arabia \\ Correspondence should be addressed to H. A. Alassiry; h.asiri99@gmail.com
}

Received 11 April 2016; Revised 17 June 2016; Accepted 7 July 2016

Academic Editor: Paul S. Szalay

Copyright @ 2016 A. A. Mustafa et al. This is an open access article distributed under the Creative Commons Attribution License, which permits unrestricted use, distribution, and reproduction in any medium, provided the original work is properly cited.

\begin{abstract}
The aim of this research is to provide some insights into the ability of the sixth year medical students and interns to recall theoretical knowledge of pharmacology. A cross-sectional study was conducted among students who graduated from three different medical schools in Riyadh, Saudi Arabia. A questionnaire was distributed to male and female students in 3 different colleges of medicine. The questionnaire included demographic information and ten multiple choice questions (MCQs) on basic pharmacology. Out of the 161 students, there were 39 females (24\%) and 122 males (76\%). A total of 36 (22\%) students studied at a traditional learning school whereas 125 (78\%) students studied at problem based learning (PBL) schools. The students were recruited from three universities: KSU, KSAU-HS, and KFMC-COM. In general, 31 students (19\%) of the participants scored $\geq 7$ out of 10, 77 students (48\%) of them obtained a correct score of (4-6) out of 10, and 53 students (33\%) scored less than 4 . The study showed no statistically significant difference in recalling pharmacology between traditional school and problem based learning school except for those who prepared for exams. Results suggest that pharmacology is a difficult subject. Reevaluations are needed in the way of teaching pharmacology.
\end{abstract}

\section{Introduction}

During the last years, problem-based learning has been widely recognized as a method to deliver medical information. In fact, about 60 medical schools worldwide have adopted this method either alone or as part of traditional learning [1]. The PBL method allows students to be able to guide their own learning and motivates them to incorporate knowledge with a problem without been constrained by traditional method of learning. In lecture-based learning, the students focus more on passing examination rather than learning [2].

Prescribing medicines safely and effectively is considered as one of the major issues in the medical field. For that reason, it is considered as a challenge of graduate medical students. The traditional learning schools have been criticized for not teaching the safe way of prescribing the medications. On the other hand, problem-based learning (PBL) is recommended based on its evidence-based treatment guidelines which had proven to be more useful for prescribing habits [3]. Clinical pharmacology is considered as a teaching and research subject for 50 years. However, it is not established until now as a medical specialty in many countries.

The WHO reports that the effective use of drugs should be the target by improving the function of clinical pharmacology; also, it should improve students' knowledge through research. Furthermore, WHO concluded that there is a gap between the availability of academic expert knowledge in pharmacology and its utilization in health care [4].

Many medical schools use PBL method of learning as it is without any modification to the curriculum. However, some of the medical schools combine PBL curriculum with 
the traditional curriculum of learning [5-8]. Involving PBL in medical curriculum is for many reasons, to fill fully the requirements of community by increasing the number of professionals, to compensate the deficiency in the traditional learning, to cope with demands of the rapid increase of information in many different aspects of knowledge.

Undergraduate medical students are satisfied with the PBL method and believed it enhances many qualities of the learning process and that is according to research published in Saudi Arabia. However, there is a need to further investigate the perception of medical students regarding different components of this approach [9].

The curriculum of college of medicine in Saudi Arabia is composed of seven years. The first two years are comprised of basic sciences like Pharmacology, Anatomy, Pathology, and so forth. During the second two years, aspects of all the major clinical disciplines are introduced. Most of the teaching occurs in the college, with one day a week available for patient and doctor sessions in the hospital. In the clinical years, the focus shifts toward full-time learning in a clinical practice setting. During years 5 and 6 , a student undertakes a series of clinical attachments in medicine and surgery that includes rotations in Mental Health, Anesthesia, Critical Care, Otolaryngology, Ophthalmology, and Dermatology, in addition to longitudinal rotations in Emergency Medicine. The final year is a medical internship, which is a transitional period for newly graduated doctors with rotations in different specialties. We chose sixth-year medical and internship students to test their ability to recall the theoretical knowledge of pharmacology. We think that medical students in these years tend to forget basic sciences including pharmacology and also maybe because of clinical textbooks do not provide detailed coverage of basic science background, and the basic concepts are generally not required in the exams, so they are forgotten over the years.

The College of Medicine, King Saud bin Abdulaziz University for Health Sciences (KSAU-HS), has been established in 2005 and adopted PBL curriculum. KSAU-HS is one of the leading universities in implementing PBL approach in Saudi Arabia. This study was carried out to provide some insights on the ability of the sixth year medical students and interns to recall theoretical knowledge of pharmacology.

\section{Methods}

161 interns and sixth year medical students were recruited from three medical schools in Riyadh, Kingdom of Saudi Arabia, from November 2013 to February 2015 for this crosssectional study. Three universities were King Saud University (KSU), King Saud bin Abdulaziz University for Health Sciences (KSAU-HS), and King Fahad Medical City-College of Medicine (KFMC-COM). The study was based on a structured questionnaire containing ten basic pharmacology MCQs (see the list below) that the students and interns were supposed to recall from their knowledge; the questionnaire is self-administered and anonymous. The questionnaire was developed in light of the stated objectives and purposes of the study. Methodologies of some relevant published researches were reviewed and relevant factors shown to affect the implementation of PBL approach and were selected to be utilized in the questionnaire. The questionnaire was distributed to the students who verbally accepted to participate in this study as they gathered in one class which they are usually supposed to have during one day of the week. They were given a duration of ten minutes to complete the questionnaire without allowing them to open books or talk to their colleagues. Then, the sample was collected immediately.

The following list shows questions covering many areas of basic and clinical pharmacology validated and answered by the participants after filling the other parts of the questionnaire. Time slot was $10 \mathrm{~min}$ for each participant and while not allowing opening books or talking to colleagues.

(i) Which one of the following drugs is contraindicated in hypertensive patients with hyperkalemia?
(A) Frusemide
(B) Amiloride
(C) Hydrochlorothiazide
(D) Mannitol
(E) Acetazolamide

(ii) Which one of the following drugs is used in the treatment of osteoporosis?
(A) Corticosteroids
(B) Heparin
(C) Etidronate
(D) Thyroxine
(E) Furosemide

(iii) Which one of the following antiarrhythmic drugs may cause corneal micro deposits?
(A) Mexiletine,
(B) Amiodarone
(C) Bretylium
(D) Diospyramide
(E) Adenosine

(iv) Which one of the following drugs relieves depression by selectively inhibiting the reuptake of serotonin?
(A) Imipramine
(B) Nortriptyline
(C) Citalopram
(D) Amitriptyline
(E) Doxepin

(v) Which one of the following drugs is used as prophylaxis by inhalation for asthmatic patients?
(A) Theophylline citrate
(B) Salbutamol sulphate
(C) Aminophylline citrate 
(D) Terbutaline sulphate

(E) Cromolyn sodium

(vi) Which of the following is a clinical use of therapeutic doses of aspirin?

(A) Relief of pain of myocardial infarction

(B) A bronchodilator effect in asthmatics

(C) Relief of inflammation in rheumatoid arthritis

(D) Treatment of hypertension

(E) An antipyretic effect in children

(vii) Type A adverse drug reactions:

(A) Can not be managed by dose adjustments

(B) Are not predictable

(C) Have immunological basis

(D) Are dose-related

(E) Result from receptor adaptation

(viii) Metformin is not recommended in male patients with serum creatinine above $1.5 \mathrm{mg} \%$ as it may produce:
(A) Lactic acidosis
(B) Hyperglycemia
(C) Insulin resistance
(D) Hyperkalemia
(E) Bladder neck obstruction

(ix) Which one of the following drugs is a non- hormonal treatment of menopausal vasomotor symptoms?
(A) Low dose of clonidine (dixarit)
(B) Dopamine.
(C) Tibolone
(D) Conjugated equine estrogens (Premarin)
(E) Norgestrel

(x) Vancomycin:

(A) Inhibits bacterial cell wall synthesis

(B) Is effective against Gram negative aerobic organisms

(C) Is well absorbed from the gut

(D) Gives rise to hypertension if given too rapidly

(E) Stimulates the release of cytokines from skin.

Other information included age, gender, nationality, graduation year, medical school, training hospitals, current rotation, and whether they were preparing for board examinations such as United States Medical License Exam (USMLE), the Medical Council of Canada Evaluating Examination (MCCEE), and Saudi License Exam (SLE).

The results of questionnaire were entered into an Excel sheet and SPSS software was used for the purpose of analysis. Descriptive statistics was used in numeric form to describe quantitative variables. Frequency distribution was done to describe the qualitative and quantitative variables. Association between different variables was analyzed using Chi-square test for qualitative data. Statistical significance considered $P \leq 0.05$.

\section{Results}

Out of 161 participants recruited for this study 122 representing $76 \%$ were males and 39 (24\%) were females (Table 1). One hundred and twenty-five (78\%) graduated from medical schools using the PBL system, whereas 36 (22\%) were from the same schools using the traditional learning approach. The participants were distributed in their training program into different specialties. One hundred and twenty-three (23\%) of the participants were preparing for external or internal agencies qualifying examinations, for example, USMLE, MCCEE, and SLE.

The MCQs in the study questionnaire were marked out of ten. Only 31 participants scored $\geq 7$ while 77 scored between 4 and 6 and 53 scored $\leq 4$ (Table 2). The mean for all the participants marks was found to be $4.51 \pm 1.97$; for those who graduated from medical schools adopting traditional system it was $4.44 \pm 1.99$, whereas for graduates from medical schools adopting the PBL system it was $4.75 \pm 1.91$. It revealed that there is no significant correlation between the two types of study systems and scores attained by the participants $(P=$ 0.41) (Table 3).

Associations of participants' scores with other parameters in the questionnaire were elucidated. The time of graduation, type of medical school, and current rotation when participating in the study showed no significant association with the scores of the participants when answering the basic pharmacology questions in questionnaire. However, the mean score for female gender was $5.38 \pm 1.74$, whereas the mean score for male gender was $4.23 \pm 1.97$. It revealed a statistically significant difference between the gender and score attained by the participants $(P=0.001)$. The mean score for participants who were preparing for external or internal agencies qualifying examinations was $5.16 \pm 2.06$, whereas the mean score for participants not preparing was $4.32 \pm 1.91$. It showed a significant association between preparing for exam or not and score attained by the participants $(P=0.02)$ (Table 3).

\section{Discussion}

The main finding of this study showed no statistical difference in recalling pharmacology between traditional school and PBL school except for those who prepared for exams.

Pharmacology teaching method in the PBL system has been improved and that is because of integrating pharmacology review session, pharmacology lectures, addition of more pharmacology questions, and clear learning objectives. The PBL method has a greater effect on USMLE score of medical students [10].

In a study conducted in Nepal by Shankar et al., they concluded that there is a lack of knowledge in medical students in pharmacology and that there is an evidence of weakness in the practice of clinical pharmacology. Due to that reason, they chose to look for different techniques to teach this important subject in medical schools. So, they distributed a questionnaire to different groups of students who were asked to answer clinical pharmacological questions. The results showed low score of students who answered 


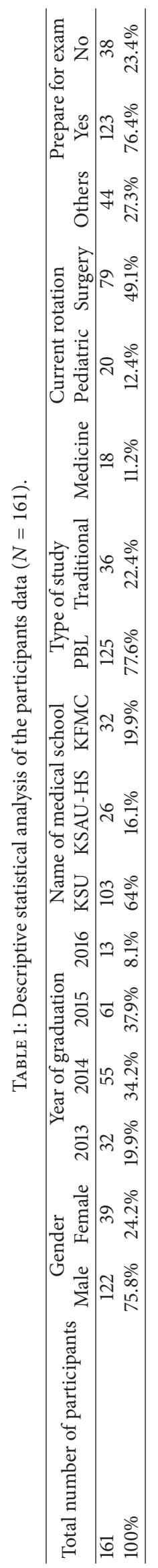


TABLE 2: Percentage of participants attained marks.

\begin{tabular}{lcc}
\hline Score & Number of students & $\%$ \\
\hline$\geq 7$ & 31 & $19.3 \%$ \\
Score $\geq 4$ to 6 & 77 & $47.8 \%$ \\
Score $\leq 4$ & 53 & $32.9 \%$ \\
\hline Total & 161 & $100 \%$ \\
\hline
\end{tabular}

TABLE 3: Score according to background variables.

\begin{tabular}{lccc}
\hline Variable & Mean & SD & $P$ value \\
\hline Gender & & & \\
$\quad$ Male & 4.23 & \pm 1.97 & 0.001 \\
$\quad$ Female & 5.38 & \pm 1.74 & \\
\hline Year of graduation & & & \\
2013 & 4.69 & \pm 1.73 & \\
2014 & 4.87 & \pm 2.20 & 0.117 \\
2015 & 4.03 & \pm 1.90 & \\
2016 & 4.77 & \pm 1.58 & \\
\hline Type of medical school & & & \\
$\quad$ PBL & 4.75 & \pm 1.91 & 0.409 \\
$\quad$ Traditional & 4.44 & \pm 1.99 & \\
\hline Preparation for exam & & & \\
Yes & 5.16 & \pm 2.06 & 0.02 \\
$\quad$ No & 4.31 & \pm 1.91 & \\
\hline Rotation when participated & & & \\
$\quad$ Medicine & 5.06 & \pm 1.69 & \\
Pediatric & 4.80 & \pm 1.98 & 0.303 \\
Surgery & 4.23 & \pm 1.88 & \\
Others & 4.66 & \pm 2.20 & \\
\hline
\end{tabular}

the questionnaire. The students asked for more sessions in pharmacology and wanted an improvement of the teaching technique and that is because they knew their weakness [11].

In 2012, there was a study conducted by Shankar et al. and they did an assessment for the second year medical students. After that, they did a new module of teaching pharmacology and then reassessed the same students. The assessment showed a big difference and high scores of the students. Based on that, medical schools should recognize and choose the most appropriate learning method according to the outcome of their students and the tough subjects [12].

In 2012, a research was done by Gautam et al. as part of the Basic Science Survey Series for Dentistry. The survey was designed to assess the effect of recent curricular changes between system-based learning and others. Course directors reported that curricular changes affect their pharmacology lecturers [13].

Jafari, in 2014, compared students' satisfaction of two different approaches (team-based learning versus conventional lectures). The students were divided into two parts. The first part used the conventional system and the second part used the team-based learning. The result showed that students' marks improved significantly in the second part, showing that team-based learning style of teaching affected the students' outcome and improved their confidence during work [14].

Poor prescribing is what pushed Likic et al. to study a pharmacology teaching method of the final year of medical students. He compared two medical schools with different style after they had a pharmacology course. The result showed no significant differences between them. His result might support the idea of unifying teaching approach of pharmacology universally [15].

In 2014, there was a study conducted by Shankar et al. and the participants showed positive opinions. They said that the integrated, problem-based learning session prepared them well to be ready for future practice and future licensing examinations. This result is in agreement with our present finding that students who are preparing for licensing examinations did better than those who were not. The reason for such better score may be related to the fact that problem-based learning style encouraged group work and active learning among students and made them more recognized for their course material. However, our study's sample size is larger than that study and with a variety of students' levels; it showed no significant differences in the final results of the PBL and traditional learning method [16].

In 2014, there was a study conducted by Hamza et al. which is a cross-sectional study for the topic of Recall of the Knowledge of Biochemistry for Interns after Graduation from Medical Schools; the result showed that among ten basic biochemistry questions $<10 \%$ of the participants answered with score more than or equal to 7 whereas $64 \%$ scored more than or equal to $4-6$ and the remaining $26 \%$ scored less than 4. There is no significant correlation with score in gender, training rotation, preparation for examinations, and time since graduation. However, there is significant correlation with score in teaching method delivered by their schools of graduation with $P$ value of 0.006 [17]

There were 2 main limitations of this research. The first one is that the research was conducted on a small sample size; those who attended the class were enthusiastic and answered the questionnaire. The second one is that because of the time limit the research was conducted only on three medical schools.

Although our present study revealed no significant differences between traditional and PBL methods, the exact reason is not known. This finding may be explained by the fact that the PBL system is a new method of learning in Saudi Arabia and it is applied as a hybrid method rather than a pure PBL. Changing strategy should be considered to help teach pharmacology to medical students. New methods of learning should be adopted to increase the students' motivation in pharmacology. We recommend to give more attention to the way of teaching pharmacology. Since other studies had shown a better outcome of the PBL approach than the traditional one, it may be recommended to unify the study of pharmacology to be taught by PBL sessions.

\section{Competing Interests}

The authors declare that they have no competing interests. 


\section{Authors' Contributions}

A. A. Mustafa, H. A. Alassiry, A. Al-Turki, and N. Alamri contributed equally to this work.

\section{References}

[1] G. R. Norman and H. G. Schmidt, "The psychological basis of problem-based learning: a review of the evidence," Academic Medicine, vol. 67, no. 9, pp. 557-565, 1992.

[2] A. Kaufman, "Commentary on 'making doctors-a new approach," Teaching and Learning in Medicine, vol. 1, no. 2, p. 67, 1989.

[3] P. R. Shankar, "Ten basic Competencies for Undergradute Pharmacology education at KIST Medical college, Lalitpur, Nepal Ten basic competencies for undergraduate pharmacology education at KIST," Australasian Medical Journal, vol. 4, no. 12, pp. 677-682, 2011.

[4] F. Sjöqvist, "Development of clinical pharmacology as a medical speciality in Europe-The roles of WHO, IUPHAR and EACPT,' Basic and Clinical Pharmacology and Toxicology, vol. 115, no. 2, pp. 172-178, 2014.

[5] P. T. Jayawickramarajah, "Curricular reforms in medical schools," Bahrain Medical Bulletin, vol. 8, pp. 47-53, 1986.

[6] D. T. A. Vernon and R. L. Blake, "Does problem-based learning work? A meta-analysis of evaluative research," Academic Medicine, vol. 68, no. 7, pp. 550-563, 1993.

[7] J. E. Des Marchais, "A student-centred, problem-based curriculum: 5 years' experience," Canadian Medical Association Journal, vol. 148, no. 9, pp. 1567-1572, 1993.

[8] J. A. Colliver, "Effectiveness of problem-based learning curricula: research and theory," Academic Medicine, vol. 75, no. 3, pp. 259-266, 2000.

[9] S. A. Al-Damegh and L. A. Baig, "Comparison of an integrated problem-based learning curriculum with the traditional discipline-based curriculum in KSA," Journal of the College of Physicians and Surgeons Pakistan, vol. 15, no. 10, pp. 605-608, 2005.

[10] K. D. Karpa and K. E. Vrana, "Creating a virtual pharmacology curriculum in a problem-based learning environment: one medical school's experience," Academic Medicine, vol. 88, no. 2, pp. 198-205, 2013.

[11] P. R. Shankar, N. Jha, O. Bajracharya, S. B. Gurung, and K. K. Singh, "Feedback on and knowledge, attitude, and skills at the end of pharmacology practical sessions," Journal of Educational Evaluation for Health Professions, vol. 8, article 12, 2011.

[12] P. R. Shankar, K. K. Singh, and R. M. Piryani, "Knowledge, attitude and skills before and after a module on pharmaceutical promotion in a Nepalese medical school," BMC Research Notes, vol. 5, article 8, 2012.

[13] M. Gautam, D. H. Shaw, T. D. Pate, and H. W. Lambert, "Pharmacology education in North American dental schools: the basic science survey series," Journal of Dental Education, vol. 77, no. 8, pp. 1013-1021, 2013.

[14] Z. Jafari, "A comparison of conventional lecture and team-based learning methods in terms of student learning and teaching satisfaction," Medical Journal of the Islamic Republic of Iran, vol. 28, article 5, 2014.

[15] R. Likic, C. White, S. Cinti et al., "Online learning applied to a course on rational therapeutics: an international comparison between final year students of two medical schools," British
Journal of Clinical Pharmacology, vol. 75, no. 2, pp. 373-380, 2013.

[16] P. R. Shankar, R. Balasubramanium, N. R. Dwivedi, and V. Nuguri, "Student feedback about the integrated curriculum in a Caribbean medical school," Journal of Educational Evaluation for Health Professions, vol. 11, article 23, 2014.

[17] M. A. Hamza, A. E. T. Idris, A. Almohanna et al., "Recall knowledge of biochemistry for interns after graduation from medical schools," International Journal of Bioscience, Biochemistry and Bioinformatics, vol. 3, no. 1, p. 16, 2013. 


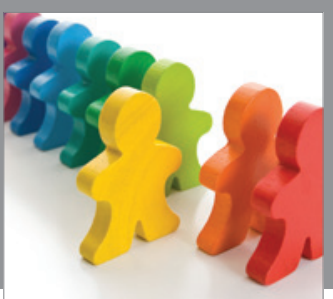

Autism

Research and Treatment
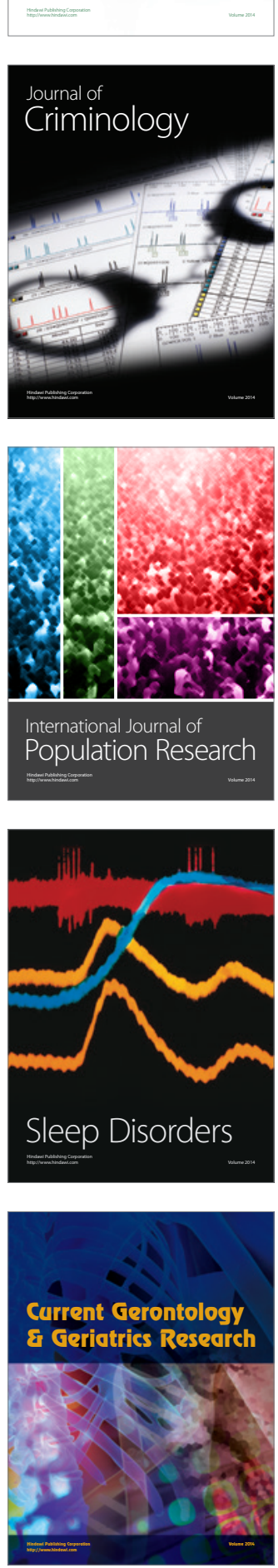

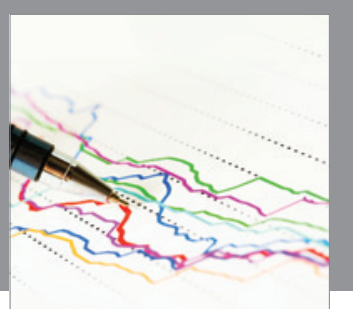

Economics

Research International
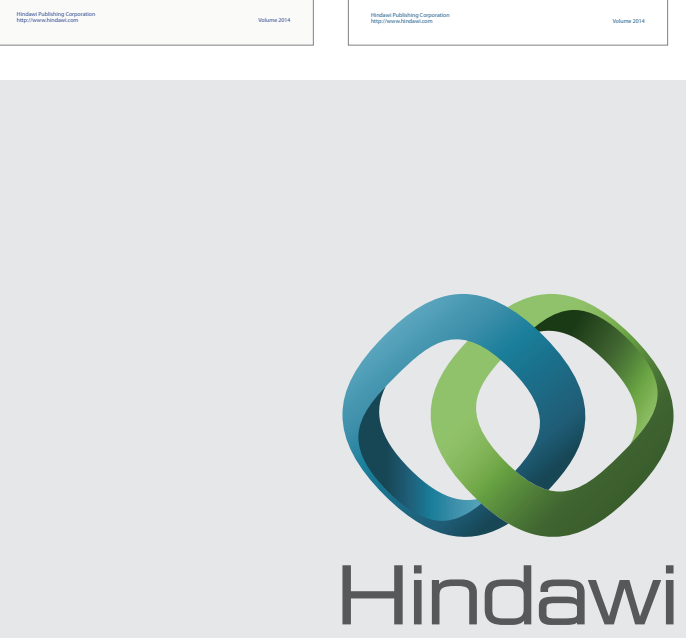

Submit your manuscripts at

http://www.hindawi.com
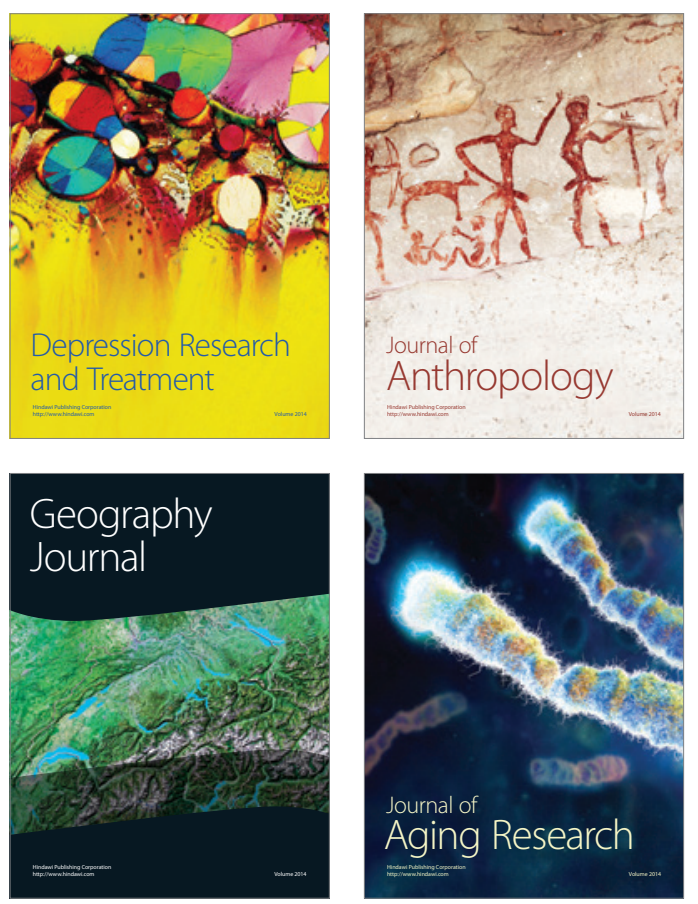
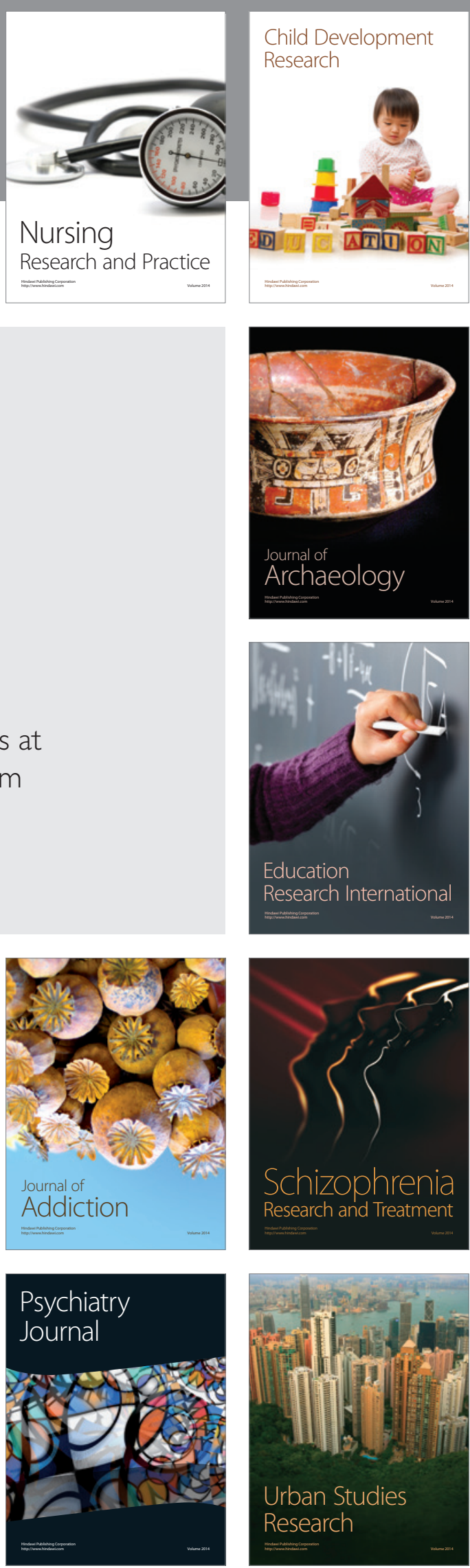